\title{
Thermodynamics Performance Analysis of Solar Stirling Engines
}

\author{
A. Asnaghi, S. M. Ladjevardi, P. Saleh Izadkhast, and A. H. Kashani \\ Renewable Energy Department, Energy and Environment Research Center, Niroo Research Institute, Ministry of Energy, \\ P.O. Box 14665 517, Tehran, Iran
}

Correspondence should be addressed to A. Asnaghi, asnaghi_a@yahoo.com

Received 3 April 2012; Accepted 2 May 2012

Academic Editors: W. He and K. Sumathy

Copyright (C) 2012 A. Asnaghi et al. This is an open access article distributed under the Creative Commons Attribution License, which permits unrestricted use, distribution, and reproduction in any medium, provided the original work is properly cited.

\begin{abstract}
This paper provides numerical simulation and thermodynamic analysis of SOLO 161 Solar Stirling engine. Some imperfect working conditions, pistons' dead volumes, and work losses are considered in the simulation process. Considering an imperfect regeneration, an isothermal model is developed to calculate heat transfer. Hot and cold pistons dead volumes are accounted in the work diagram calculations. Regenerator effectiveness, heater and cooler temperatures, working gas, phase difference, average engine pressure, and dead volumes are considered as effective parameters. By variations in the effective parameters, Stirling engine performance is estimated. Results of this study indicate that the increase in the heater and cooler temperature difference and the decrease in the dead volumes will lead to an increase in thermal efficiency. Moreover, net work has its maximum value when the angle between two pistons shaft equal to 90 degrees while efficiency is maximum in 110 degrees.
\end{abstract}

\section{Introduction}

The urgent need to preserve fossil fuels and use renewable energies has led to the use of Stirling engines, which have excellent theoretical efficiency, equivalent to the related Carnot cycle. They can consume any source of thermal energy (combustion energy, solar energy, etc.) and they make less pollution than the traditional engines, [1].

A Stirling cycle machine is a device, which operates in a closed regenerative thermodynamic cycle. In the ideal cycle of the Stirling engine, the working fluid is compressed at constant temperature, heated at constant volume, expanded at constant temperature, and cooled at constant volume. The flow is regulated by volume changes so there is a net conversion of heat to work or vice versa.

The Stirling engines are frequently called by other names, including hot-air or hot-gas engines, or one of a number of designations reserved for particular engine arrangement.

Numerous applications of Stirling engines were raised during the 19th century and at the beginning of the 20th century. Stirling engine in the 19th century was confined largely by the metallurgical possibilities and problems of the time. By these reasons, the engine was finally pushed back by newly developed internal combustion engines. The Stirling engine was almost forgotten until the 1920s.

It was only in 1938, a small Stirling engine with an output of $200 \mathrm{~W}$ by Mr. N. V. Philips which stimulated interest in this engine type again. Development in material production technologies that took place in the 1950s opened new perspectives as well for the Stirling engine.

In the course of 1969-1970, Philips developed a drive unit with a rhombic mechanism for a municipal bus. A detailed calculation finally showed that, with a batch of 10000 pieces annually, the price would still be 2.5 times higher than that of a compression ignition engine of the same output due to the substantial complexity of the engine.

In the 1970s United Stirling worked hard on the development of a drive unit for passenger cars. One of the following V4X35 types was fitted in the Ford Taurus car in 1974. Despite the satisfactory results of a driving test covering $10,000 \mathrm{~km}$, series production was never commenced due to the price of the drive unit.

High heat efficiency, low-noise operation, and ability of Stirling engines to use many fuels meet the demand of the effective use of energy and environmental security. Stirling engine-based units are considered best among the most 
effective low-power range solar thermal conversion units [2].

On the other side, the main disadvantages of Stirling engines are their large volume and weight, low compression ratio, and leakage of working fluid from the engine inner volume. To increase the specific power of Stirling engines, a number of methods have been developed, such as using hydrogen or helium as working fluid at high charge pressure, increasing the temperature difference between hot and cold sources, increasing the internal heat transfer coefficient and heat transfer surface and using simple mechanical arrangements, for example, a free piston Stirling engine [3].

The Stirling engine performance depends on geometrical and physical characteristics of the engine and on the working fluid gas properties such as regenerator efficiency and porosity, dead volume, swept volume, temperature of sources, pressure drop losses, and shuttle losses.

A machine that utilizes the Stirling cycle could function as an engine that converts heat energy from an appropriate heat source into kinetic energy, or, by employing the reverse cycle, as a refrigerator that can achieve low temperatures or provide a heat-absorbing effect by the injection of kinetic energy from an electric motor. The Stirling engine has also been proposed as a driver for electricity generators and heat pumps, and its practical applications have been realized. Conventionally, fossil fuels and solar energy have been considered as potential heat sources; more recently, however, the practical applications of engines that utilize biomass or the waste heat generated from diesel engines as fuel have been discovered [4].

The thermal limit for the operation of a Stirling engine depends on the material used for its construction. In most instances, the engines operate with a heater and cooler temperature of 923 and $338 \mathrm{~K}$, respectively. Engine efficiency ranges from about 30 to $40 \%$ resulting from a typical temperature range of $923-1073 \mathrm{~K}$, and normal operating speed range from 2000 to $4000 \mathrm{rpm}$ [5].

Numerical investigations of Stirling engines have been performed by many researches. Thermodynamics analysis is the basic of almost all of these researches. Some of these researches focus on a specific part of engine, for example, regenerator [6]. Some of the others focus on a specific type of Stirling engine, for example, free piston Stirling engine [7]. Considering specific operating conditions, for example, thermoacoustic conditions, are objective in many of these researches [8]. In all of these researches, the main objective is to calculate the optimum operating condition. In the current study, maximum output power and maximum performance efficiency are considered as main objectives. Numerical model is developed using thermodynamics analysis to generate performance variations comparing different parts' characteristics and conditions.

\section{Stirling Engine Cycle}

2.1. Description. Stirling engines are mechanical devices working theoretically on the Stirling cycle in which compressible fluids, such as air, hydrogen, helium, nitrogen, or even water vapor, are used as working fluids. The Stirling engine offers possibility for having high-efficiency engine with less exhaust emissions in comparison with the internal combustion engine. The Stirling engine is an external combustion engine. Therefore, most sources of heat can power it, including combustion of any combustive material, field waste, rice husk, or the like, biomass methane and solar energy. In principle, the Stirling engine is simple in design and construction and can be operated without difficulty [9].

2.2. Application. The Stirling engine could be used in many applications and is suitable where

(1) multifueled characteristic is required;

(2) a very good cooling source is available;

(3) quiet operation is required;

(4) relatively low speed operation is permitted;

(5) constant power output operation is permitted;

(6) slow changing of engine power output is permitted;

(7) A long warmup period is permitted.

2.3. Ideal Stirling Cycle. The engine cycle is represented on PV and TS diagrams in Figure 1. The ideal cycle of the Stirling engine is formed by two isochoric processes and two isothermal processes. Consider a cylinder containing two opposed pistons with a regenerator between the pistons as shown in Figure 2. The regenerator is like a thermal sponge alternatively absorbing and releasing heat which is a matrix of finely divided metal in the form of wires or strips. The volume between regenerator and the right side piston is expansion volume and between regenerator and left side piston is compression volume. Expansion volume is maintained at heater temperature which is called hot temperature, and compression volume is maintained at cooler temperature which is called cold temperature [2].

To start with Stirling cycle, we assume that the compression space piston is at outer dead point (at extreme right side) and the expansion space piston is at inner dead point close to regenerator. The compression volume is at maximum and the pressure and temperature are at their minimum values represented by point 1 on PV and TS diagrams of Figure 1.

Four processes of the Stirling cycle are [11] as follows.

2.3.1. Process 1-2, Isothermal Compression Process. During compression process from 1 to 2 , compression piston moves towards regenerator while the expansion piston remains stationery. The working fluid is compressed in the compression space and the pressure increases from P1 to P2. The temperature is maintained constant due to heat flow from cold space to surrounding. Work is done on the working fluid equal in magnitude to the heat rejected from working gas. There is no change in internal energy and there is a decrease in entropy. 

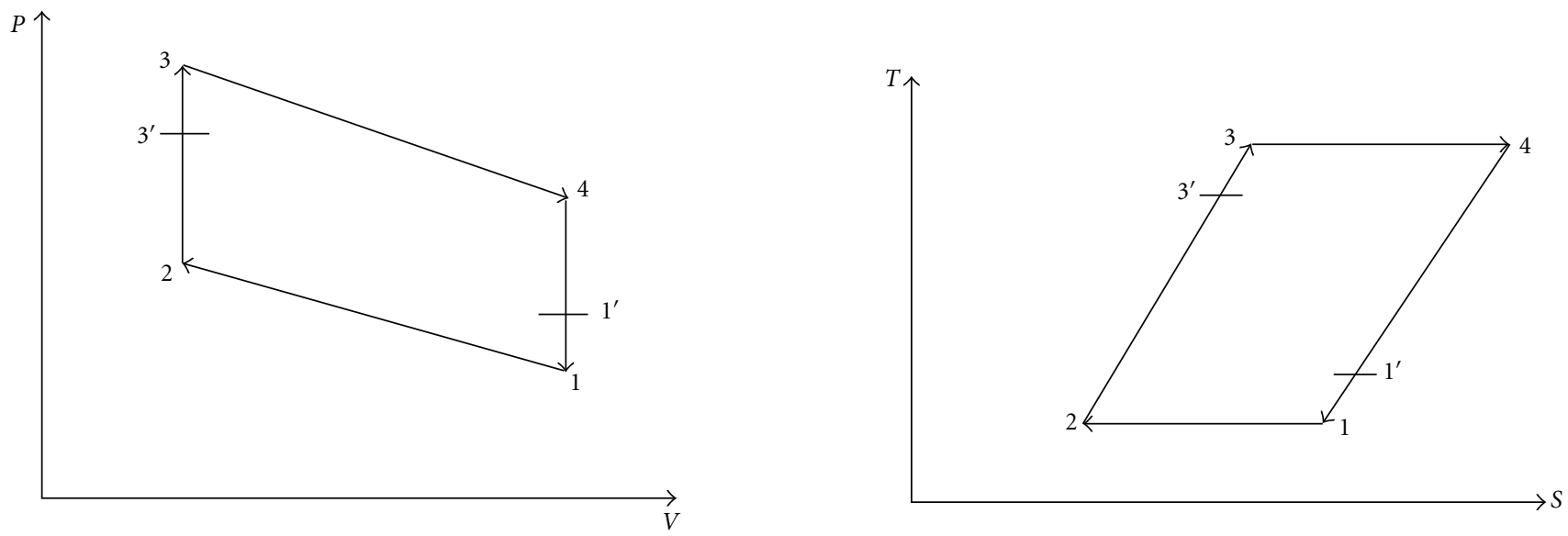

FIgure 1: $P-V$ and $T-S$ diagrams of Stirling engine.

State 1

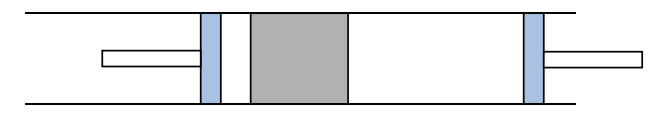

State 2

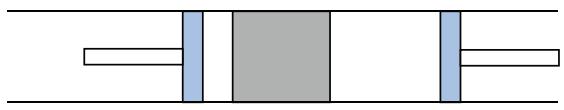

State 3

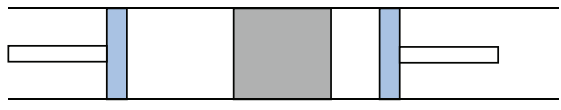

State 4

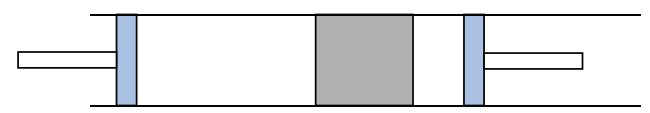

Figure 2: Stirling engine cyclic pistons' arrangements [10].

2.3.2. Process 2-3, Constant Volume Regenerative Transfer Process. In the process 2-3, both pistons move simultaneously, that is, compression piston towards regenerator and expansion piston away from regenerator, so that the volume between pistons remains constant. The working fluid is transferred from compression volume to expansion volume through porous media regenerator. Temperature of working fluid increased from $T_{1}$ to $T_{3}$ by heat transfer from regenerator matrix to working fluid. The gradual increase in temperature of working fluid while passing through regenerator causes increase in pressure. No work is done and there is an increase in the entropy and internal energy of the working fluid.

2.3.3. Process 3-4, Isothermal Expansion Process. In the expansion process 3-4, the expansion piston continues to move away from the regenerator towards outer dead piston while compression piston remains stationery at inner dead point adjacent to regenerator. As the expansion proceeds, the pressure decreases as volume increases. The temperature maintained constant by adding heat to the system from external source at $T_{3}$. Work is done by the working fluid on piston equal in the magnitude to the heat supplied. There is no change in the internal energy, but an increase in the entropy of the working fluid.

\subsubsection{Process 4-1, Constant Volume Regenerative Transfer}

Process. In the process $4-1$, both pistons move simultaneously to transfer working fluid from expansion space to compression space through regenerator at constant volume. During the flow of working fluid through regenerator, the heat is transferred from the working fluid to the regenerator matrix reducing the temperature of working fluid to $T_{1}$. No work is done; there is a decrease in the internal energy and the entropy of the working fluid.

The Stirling cycle is highly idealized thermodynamic cycle, which consists of two isothermal and two constant volume processes and the cycle is thermodynamically reversible. The first assumptions of isothermal working and heat exchange imply that the heat exchangers are required to be perfectly effective, and to do so, infinite rate of heat transfer is required between cylinder wall and working fluid. The second assumption requires zero heat transfer between walls and working fluid, both assumptions remain invalid in actual engine operation [2].

2.4. Different Mechanical Configurations. With respect to their mechanical arrangements, Stirling engines are classified into three groups: alpha, beta, and gamma. Each configuration has the same thermodynamic cycle but has different mechanical design characteristics, see Figure 3.

In the alpha-configuration, two pistons, called the hot and cold pistons, are used on either side of the heater, regenerator, and cooler. In the alpha type of mechanical arrangement, the thermodynamic cycle is performed by means of two pistons working in separate cylinders: one is held at the hot temperature and the other at the cold temperature.

In the beta-configuration, a displacer and a power piston are incorporated in the same cylinder. The displacer moves working fluid between the hot space and the cold space of the cylinder through the heater, regenerator, and cooler. The power piston, located at the cold space 


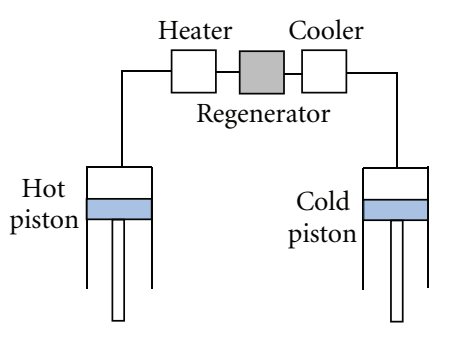

$\alpha$ configuration

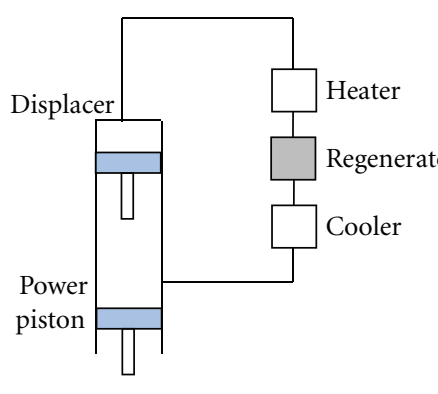

$\beta$ configuration

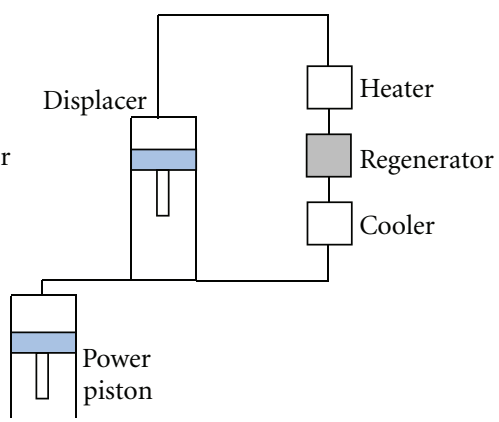

$\gamma$ configuration

FIgURE 3: The basic mechanical configurations for Stirling engine.

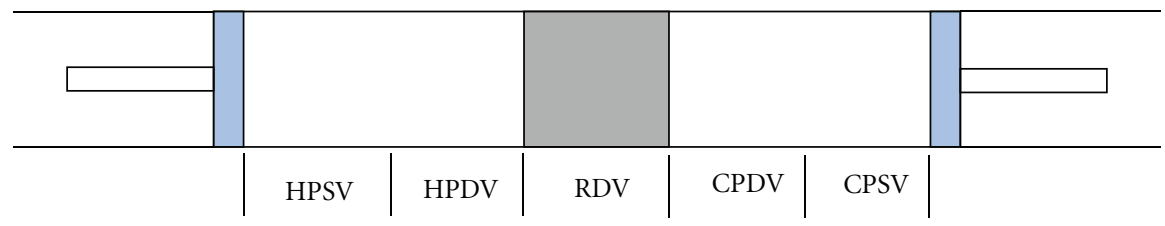

HPSV: Hot piston sweep volume CPSV: Cold piston sweep volume HPDV: Hot piston dead volume CPDV: Cold piston dead volume RDV: Regenerator dead volume

FIGURE 4: Stirling engine volumes contributions.

of the cylinder, compresses the working fluid when the working fluid is in the cold space and expands the working fluid when the working fluid is moved into the hot space.

The gamma-configuration uses separated cylinders for the displacer and the power pistons, with the power cylinder connected to the displacer cylinder. The displacer moves working fluid between the hot space and the cold space of the displacer cylinder through the heater, regenerator, and cooler. In this configuration, the power piston both compresses and expands the working fluid. The gammaconfiguration with double acting piston arrangement has theoretically the highest possible mechanical efficiency. This configuration also shows good self-pressurization. However, the engine cylinder should be designed in vertical type rather than horizontal in order to reduce bushing friction [9]. It should be noted that, in this study, the thermodynamic equations and relations for alpha type has been presented. However, the presented algorithm can be extended to two other types of Stirling engines. To do so, basic thermodynamic equations for Beta and Gamma engines arrangements can be found in [11].

2.5. Dead Volumes and Regenerator Deficiency. In the ideal Stirling cycle, it is assumed that the total heat rejected during process $4-1$ is absorbed by the regenerator and then released to the working fluid during the process 2-3. In reality, we cannot find the ideal regenerator and all of the regenerators due to their structure and used materials have deficiency. So, an imperfect regenerator cannot absorb the total heat released during process $4-1$, and consequently cannot provide the total required heat of process $2-3$. For this study, the temperatures of working fluid at exit of the imperfect regenerator are noted as $T_{3^{\prime}}$ and $T_{1^{\prime}}$. In Figure 1 , the positions of these two temperatures in $P-V$ and $T-S$ diagram are presented. Although regenerator effectiveness values of 95, 98-99, and 99.09\% have been reported, engine developers who do not have efficient-regenerator technology in hand should take into account the regenerator effectiveness, and then an analysis with imperfect regeneration should be made [5].

Total dead volume is defined as the sum of Stirling engine void volumes. The dead volumes are considered for regenerator, cold and hot pistons. It is evidenced that a real Stirling engine must have some unavoidable dead volume. In normal Stirling engine design practice, the total dead volume is approximately $58 \%$ of the total volume. Although many researchers have analyzed Stirling engines, there still remains room for further development. One can use the Schmidt equations to consider dead volumes on his/her analysis. However, ideal regeneration is assumed in the Schmidt analysis [11]. Considering Figure 2, the dead volumes contributions of Stirling engine are presented in Figure 4.

Another important issue which should be considered is the temperature of the regenerator. Correct estimating of regenerator temperature will have direct effects on the 
final results. In our approach, it is assumed that half of the regenerator dead volume is at $T_{3^{\prime}}$, and the other half is at $T_{1^{\prime}}$. Following, the effective temperature of the regenerator can be calculated by arithmetic mean or log mean of these two temperatures.

\section{Thermodynamics Equations}

The basic assumptions for the Stirling engine are as follows [11].

(i) Temperature in each gas space (cold and hot) is known and constant.

(ii) There is no pressure difference between the gas spaces.

(iii) Ideal gas law can be used for the working fluid.

(iv) There is no leakage into or out of the working fluid space.

3.1. Regenerator Effectiveness. Effectiveness of a regenerator for hot and cold sides is defined as

$$
\begin{gathered}
E_{H}=\frac{T_{3^{\prime}}-T_{2}}{T_{3}-T_{2}}=\frac{T_{3^{\prime}}-T_{C}}{T_{H}-T_{C}}, \\
E_{C}=\frac{T_{H}-T_{1^{\prime}}}{T_{H}-T_{C}} .
\end{gathered}
$$

For ideal regenerator, the effectiveness is equal to one. To consider the Stirling engines which do not use regenerator, the effectiveness should be set equal to zero. The temperatures at the exit of the regenerator are defined as

$$
\begin{aligned}
& T_{3^{\prime}}=T_{C}+E_{h}\left(T_{H}-T_{C}\right), \\
& T_{1^{\prime}}=T_{H}-E_{c}\left(T_{H}-T_{C}\right) .
\end{aligned}
$$

If we consider that $Q_{2-3^{\prime}}=Q_{4-1^{\prime}}$, the regenerator should have same effectiveness for cold and hot sides which means $E_{H}=E_{C}=E$.

As it is discussed previously, estimation of the regenerator effective temperature is important. Three main approaches for estimation of regenerator effective temperature are as follows.

(i) Arithmetic mean approach:

$$
T_{R}=\frac{T_{1^{\prime}}+T_{3^{\prime}}}{2} .
$$

(ii) Logarithmic mean approach:

$$
T_{R}=\frac{T_{3^{\prime}}-T_{1^{\prime}}}{\ln \left(T_{3^{\prime}} / T_{1^{\prime}}\right)} .
$$

(iii) Half hot space-half cold space approach:

$$
\frac{1}{T_{R}}=\frac{1}{2}\left(\frac{1}{T_{1^{\prime}}}+\frac{1}{T_{3^{\prime}}}\right) .
$$

By substitution of (2) into (3), the regenerator effective temperature will be

$$
T_{R}=\frac{T_{C}+T_{H}}{2} .
$$

As it is clear in (6), in the arithmetic mean approach the regenerator effective temperature isn't depended on the effectiveness of the regenerator. However, in the two other approaches, the effective temperature of regenerator is dependent on the regenerator effectiveness.

3.2. Volumes. It is considered that pistons have simple harmonic movements. Therefore, volumes of pistons are defined as follows:

$$
\begin{gathered}
V_{\mathrm{HP}}=\frac{V_{\mathrm{HPSV}}}{2}(1-\sin (\varphi))+V_{\mathrm{HPDV}} \\
V_{\mathrm{CP}}=\frac{V_{\mathrm{CPSV}}}{2}(1-\sin (\varphi-\mathrm{ALPH}))+V_{\mathrm{CPDV}} \\
V_{\mathrm{TV}}=V_{\mathrm{HP}}+V_{\mathrm{RDV}}+V_{\mathrm{CP}} .
\end{gathered}
$$

In these equations, $\varphi$ is the angle of crank shaft, and ALPH is the phase angle difference between hot and cold pistons, respectively.

As it is shown in Figure 4, the total dead volumes can be calculated as follows:

$$
V_{\mathrm{TDV}}=V_{\mathrm{HPDV}}+V_{\mathrm{RDV}}+V_{\mathrm{CPDV}}
$$

The dimensionless total dead volume is presented as follows:

$$
V_{\mathrm{TDV}}^{*}=\frac{V_{\mathrm{TDV}}}{V_{\mathrm{HP}}+V_{\mathrm{CP}}} .
$$

It should be noted that the utilized algorithm is independent from volume variations definitions. However, in this study simple harmonic motion is used.

3.3. Pressure Equation. It is assumed that the working gas is an ideal gas and, therefore, the ideal gas state equation can be used for it. Total mass of the working fluid is sum of hot piston volume, hot piston dead volume, regenerator dead volume, cold piston dead volume, and cold piston volume. Therefore,

$$
m_{\mathrm{TV}}=m_{\mathrm{HP}}+m_{\mathrm{RDV}}+m_{\mathrm{CP}}
$$

Each space follows the ideal gas state equation:

$$
\begin{aligned}
m_{\mathrm{HP}} & =\frac{P_{\mathrm{HP}} V_{\mathrm{HP}}}{R T_{H}}, \\
m_{\mathrm{RDV}} & =\frac{P_{\mathrm{RDV}} V_{\mathrm{RDV}}}{R T_{\mathrm{RDV}}}, \\
m_{\mathrm{CP}} & =\frac{P_{\mathrm{CP}} V_{\mathrm{CP}}}{R T_{C}} .
\end{aligned}
$$

It is assumed that the pressure in these three spaces is equal. Substituting (11) into (10), the pressure relation will be obtained as follow:

$$
m_{T}=\frac{P}{R}\left[\frac{V_{\mathrm{HP}}}{T_{H}}+\frac{V_{\mathrm{RDV}}}{T_{\mathrm{RDV}}}+\frac{V_{\mathrm{CP}}}{T_{C}}\right] .
$$


3.4. Heat and Work Values during Four Steps of the Stirling Cycle. As it is mentioned previously, the Stirling cycle consists of four steps: isothermal compression process (based on Figure 1, point 1 to 2 ), isochoric heating process (point 2 to 3 ), and isothermal expansion process (point 3 to 4 ), isochoric cooling process (point 4 to 1 ).

Having the volumes and working gas mass, one can calculate the pressure using (12). As volumes are relative to crank shaft angle (7), pressure is also proportional to crank shaft angle.

3.4.1. Work Diagram. By changing the crank shaft angle from zero to 360 degree, it would be possible to obtain $P-V$ diagram. Integrating areas of this diagram, expansion work, compression work, and net work can be calculated. For this reason, $P-V$ diagram is called as work diagram. The expansion work which theoretically occurs in process 3-4 of Figure 1 is equal to added heat. Compression work which theoretically occurs in process 1-2 of Figure 1 is equal to absorbed heat during the cycle. Therefore, by having the work diagram, added heat and absorbed heat can be calculated.

3.4.2. Isochoric Heating Process. Regenerator will provide required heat from $2-3^{\prime}$. Therefore, the remaining heat to warm the working gas from $3^{\prime}-3$ should be provided by heater. By considering that the process occurs in constant volume, the heat added during the isochoric heating process $3^{\prime}-3$ is given by

$$
Q_{3^{\prime}-3}=m C_{V}\left(T_{3}-T_{3^{\prime}}\right)=m C_{V}(1-E)\left(T_{H}-T_{C}\right) .
$$

In (13), all parameters except the mass are known. In some literatures like [5], this mass is considered equal to total mass of working fluid. In this assumption, the mass of working gas in cold dead volume is neglected.

3.5. Thermal Efficiency. Thermal efficiency of Stirling engine including dead volumes and regenerator deficiency is given by

$$
\eta_{\text {th }}=\frac{W_{\text {net }}}{Q_{\text {total input heat }}} .
$$

\section{Solution Procedure}

In what follows, the numerical solution algorithm is presented, see Figure 5. First, the values of engine dimensions and working conditions are specified. In Table 1, the basic used values are presented.

It should be noted that the conditions presented in Table 1 are the same as SOLO 161 Solar Stirling Unit which is under experimental tests in NRI.

\section{Results}

5.1. Basic Engine Performance. In Figure 6, the $P-V$ diagram of the basic engine is presented. Because the integration of area inside the $P-V$ curve indicates the net work, this diagram is called as the work diagram. In Table 2, the performance characteristics of the basic engine are provided.

\subsection{Effects of Hot Temperature}

5.2.1. Effects of Regenerator Effectiveness. Theoretically, in the $P-V$ diagram of Stirling engine (Figure 1), the hot temperature indicates the locations of point 3 and 4 . Having constant volume and mass, increase in hot temperature will results in increase of pressure of these two points. Therefore, the area of below line 3-4 will increase which means the increase in total input heat. As it is shown in Figure 7, the total input heat increases with increase in hot temperature. It should be noted that the amount of increase for lower values of regenerator effectiveness is more. The added heat during process 3-4 is equal for all regenerator effectiveness values and is equal to $E=1.0$ values. The difference is added heat during process $3^{\prime}-3$. In lower values of regenerator effectiveness, this value is higher and, therefore, more heat should be added to the engine.

Increase in hot temperature will result in increase of expansion work, the area below the line 3-4 in Figure 1. While the compression work is constant, this will lead to increase in net work. Because the regenerator effectiveness does not have effect on process 3-4 and 1-2, it does not have effect on net work. In Figure 8, variations of net work with increase in hot temperature are presented.

As it is stated before, increase in hot temperature will result in increase in total input heat and net work. When the difference between hot temperature and cold temperature is low, hot temperature from $400-600 \mathrm{~K}$, in Figure 9, an increase in hot temperature has more effects on net work than total input heat which will lead to increase in thermal efficiency. In higher values of hot temperature, hot temperature higher than $600 \mathrm{~K}$ in Figure 9, the increase rate in net work and total input heat is approximately equal, and, therefore, thermal efficiency tends to a limited value. Similar results are observed by experimental tests [12].

5.2.2. Working Gas Effects. In this study, we have fixed engine volumes and average pressure, and then the mass of working fluid is calculated. Because volumes and pressure are constant, net work is independent from working gas type. Therefore, thermal efficiency is just proportional to total input heat. Four different gases are considered, air, helium, hydrogen and nitrogen. As it is presented in Figure 10, by increase in hot temperature, helium needs lower total input heat in similar conditions. Because the net work is equal, the thermal efficiency of helium is more than other working gases which is presented in Figure 11.

\subsection{Effects of Cold Temperature}

5.3.1. Effects of Regenerator Effectiveness. Compared to hot temperature effects, increase in cold temperature has reverse 


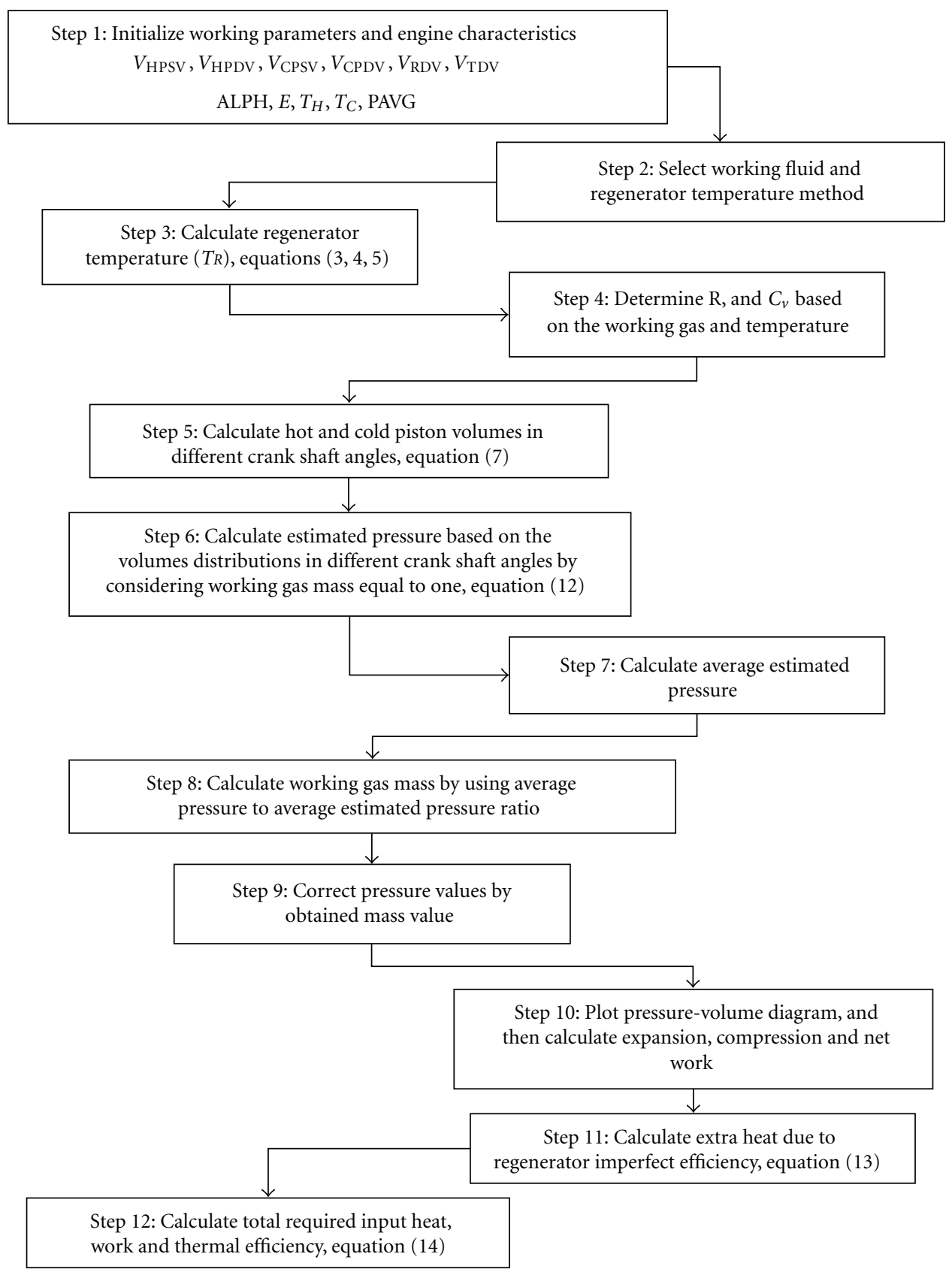

FIGURE 5: Stirling engine performance estimation procedure diagram.

TABLE 1: Values of basic engine parameters.

Hot piston sweep volume $=160.0 \mathrm{~cm}^{3}$

Hot piston dead volume $=40 \mathrm{~cm}^{3}$

Regenerator dead volume $=30.0 \mathrm{~cm}^{3}$

Regenerator effectiveness $=0.85$

Heater temperature $=923 \mathrm{~K}$

Average working pressure $=10 \mathrm{MPa}$
Cold piston sweep volume $=160.0 \mathrm{~cm}^{3}$

Cold piston dead volume $=30.0 \mathrm{~cm}^{3}$

Total dead volume $=100.0 \mathrm{~cm}^{3}$

Phase angle difference $=90.0$ degree

Cooler temperature $=300 \mathrm{~K}$

Frequency of engine $=1800 \mathrm{rpm}$

TABle 2: Performance characteristics of the basic engine.

\begin{tabular}{lcccc}
\hline Working fluid & PAVG $(\mathrm{MPa})$ & Net work $(J)$ & Thermal efficiency & Total input heat $(J)$ \\
\hline Helium & 10 & 887.993 & $26.9 \%$ & 3300.23 \\
\hline
\end{tabular}




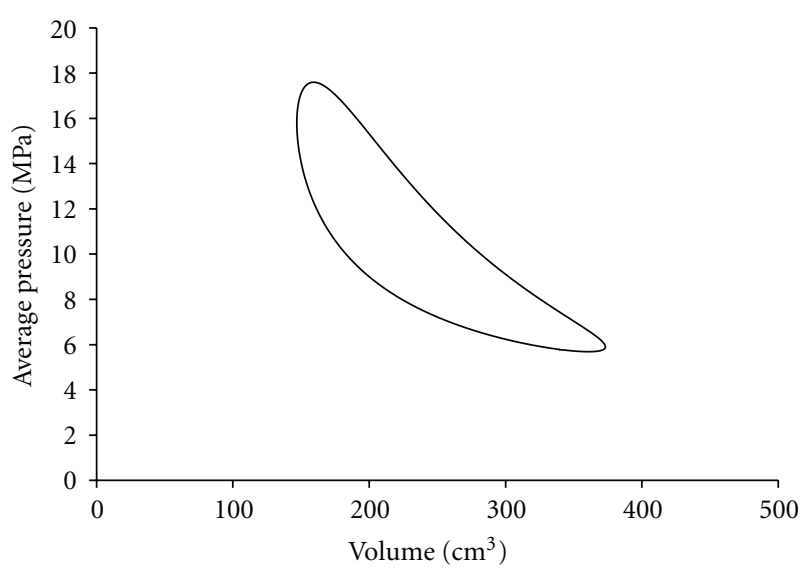

Figure 6: $P-V$ (work) diagram for the basic engine.

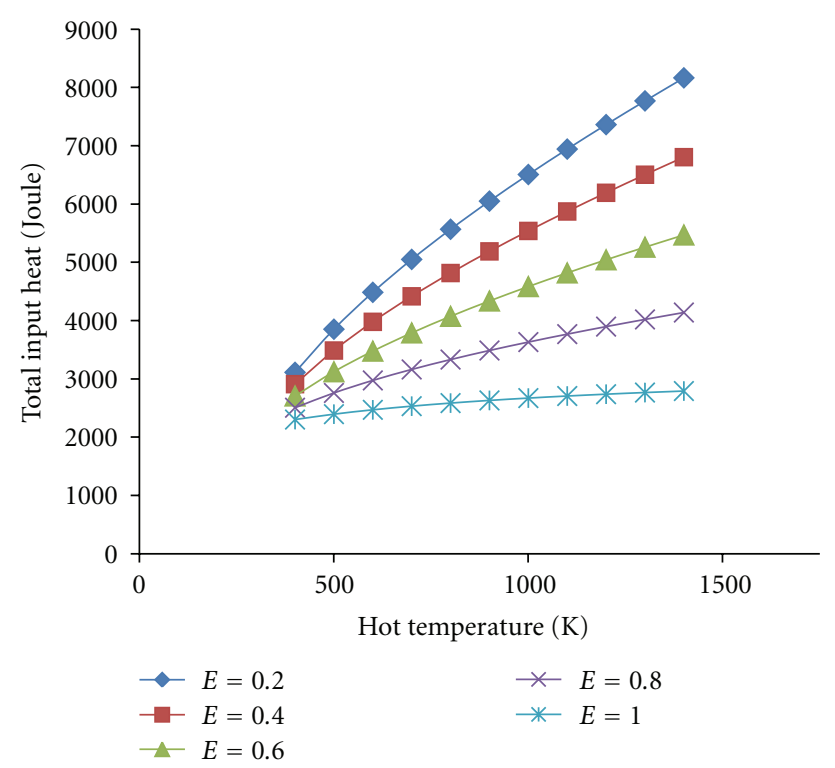

FIGURE 7: Variations of total input heat against hot temperature for different regenerator effectiveness values.

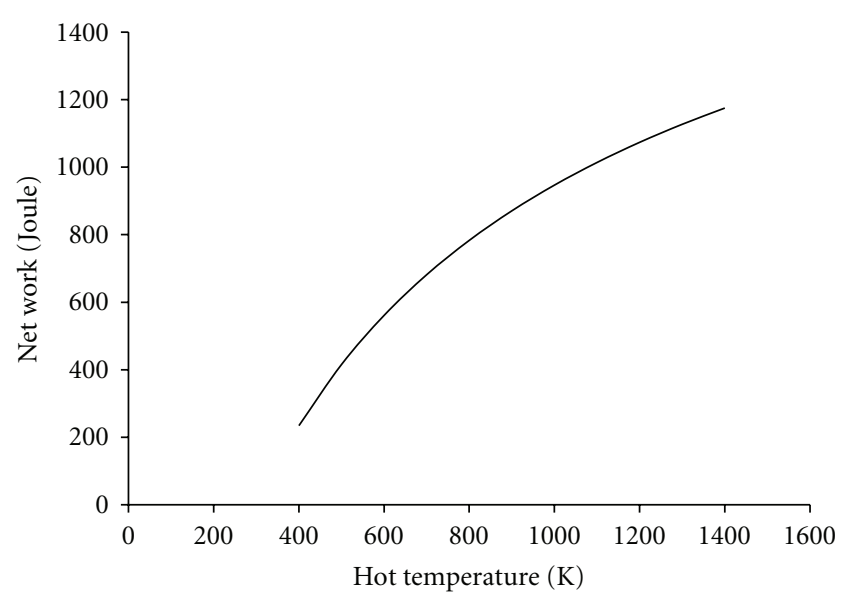

Figure 8: Variations of net work against hot temperature.

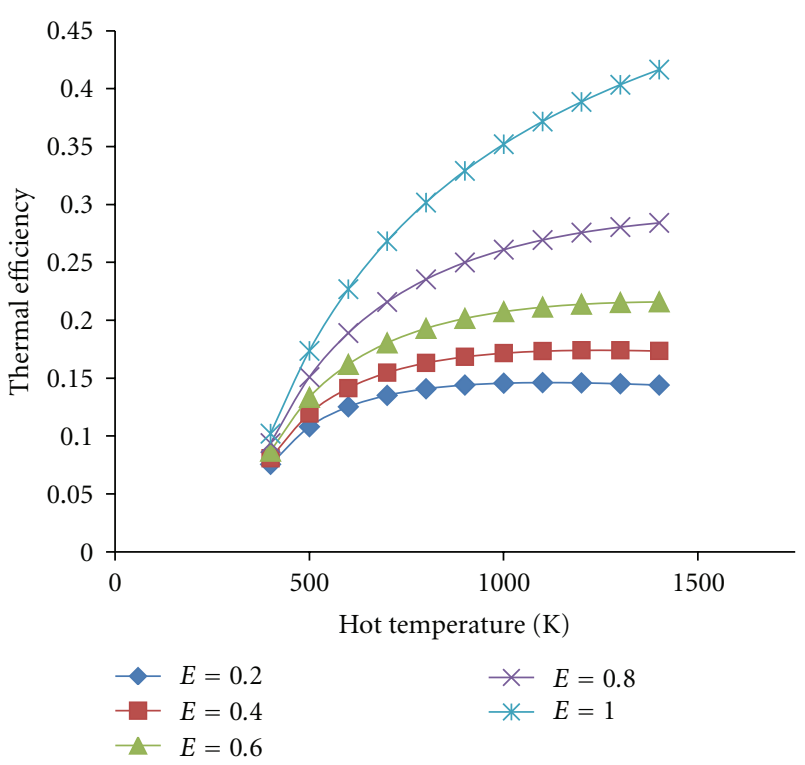

FIGURE 9: Variations of thermal efficiency against hot temperature for different regenerator effectiveness values.

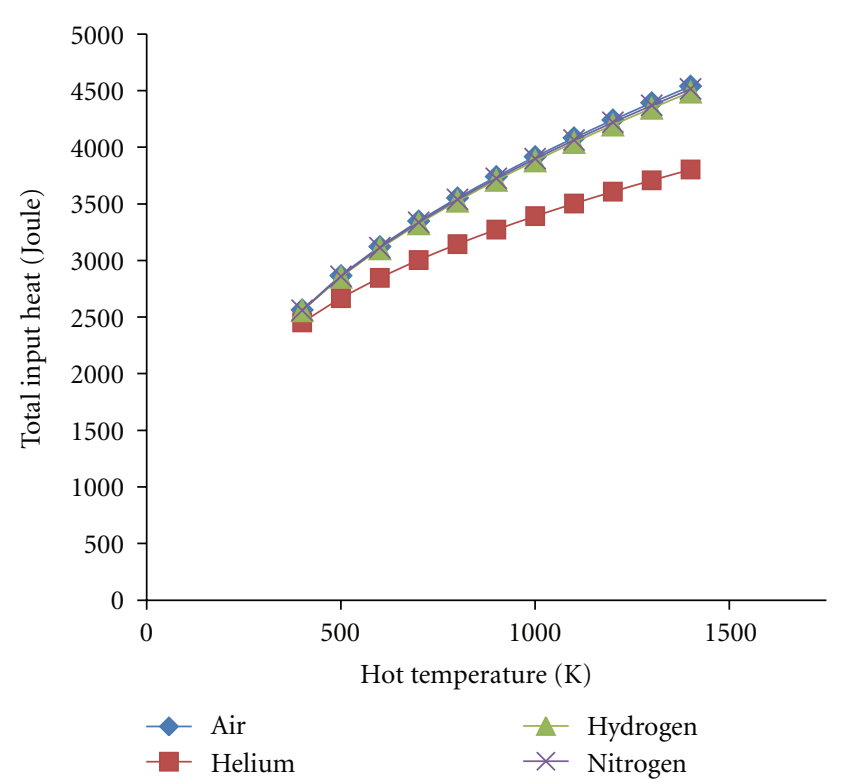

FIGURE 10: Variations of total input heat against hot temperature for different working gas types.

effects on total input heat, net work, and thermal efficiency. Although increase in cold temperature will result in decrease in total input heat which is desired, it will reduce net work which is undesired. The variations of total input heat and net work against cold temperature are presented in Figures 12 and 13.

Because the decrease in net work is more than decrease amount of total input heat, thermal efficiency decreases with increase in cold temperature. The amount of decrease in higher values of regenerator effectiveness is more which is shown in Figure 14. 


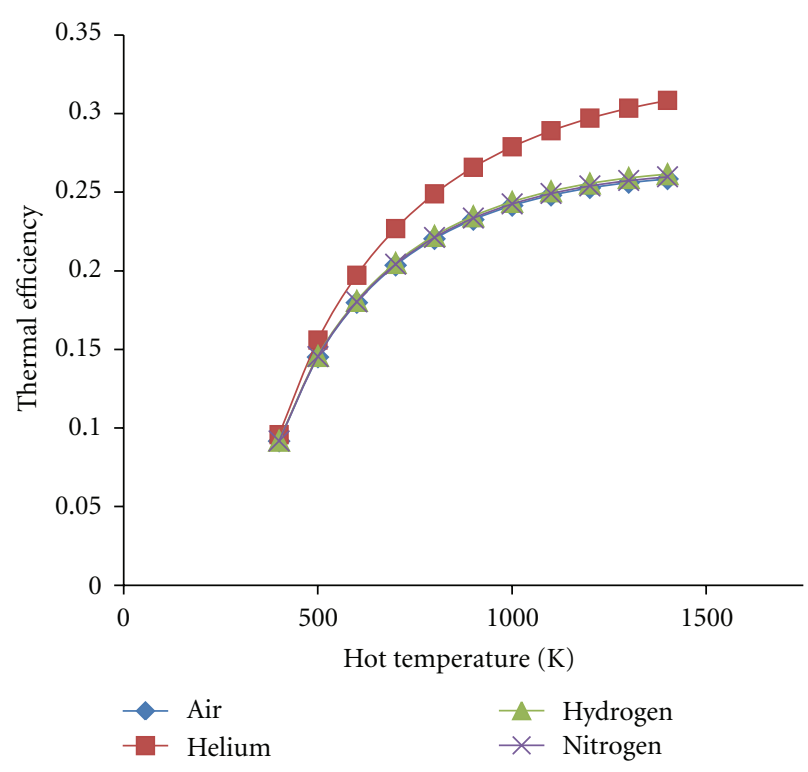

FIGURE 11: Variations of thermal efficiency against hot temperature for different working gas types.

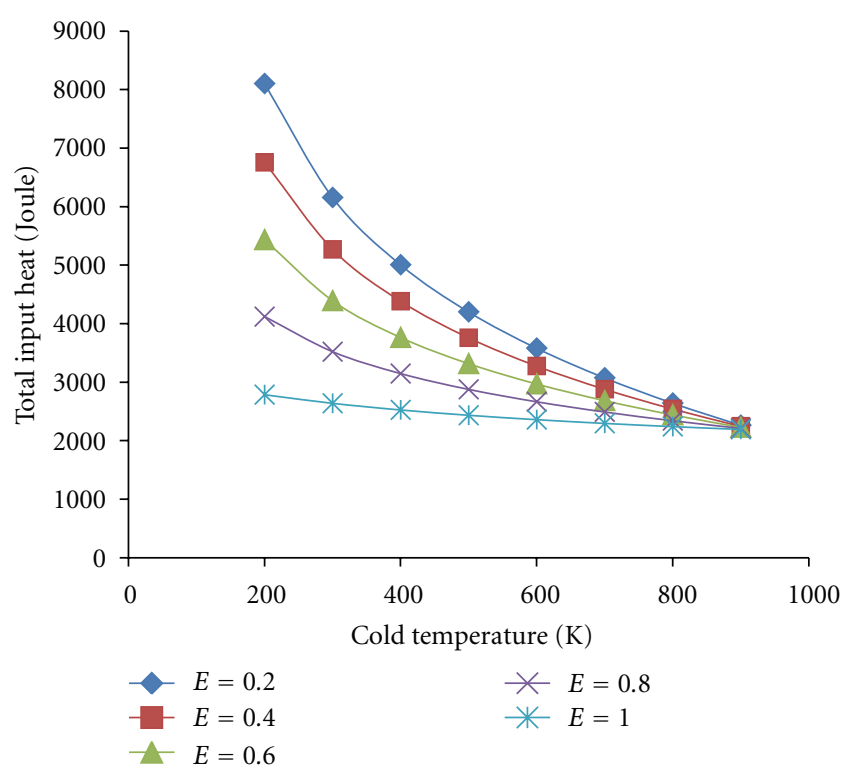

FIGURE 12: Variations of total input heat against cold temperature for different regenerator effectiveness values.

5.3.2. Working Gas Effects. In lower values of cold temperature, helium needs lower amount of total input heat compared to air, hydrogen, and nitrogen, see Figure 15. By increase in cold temperature and reduction in difference between the cold and hot temperatures, the total input heat for all gases tend to a constant value. Therefore, considering that net work is equal, helium has higher thermal efficiency which reduces by increase in cold temperature, see Figure 16.

5.4. Effects of Regenerator Effectiveness. Effectiveness of regenerator indicates the required heat during process $3^{\prime}-3$ of Figure 1. Therefore, having regenerator with higher

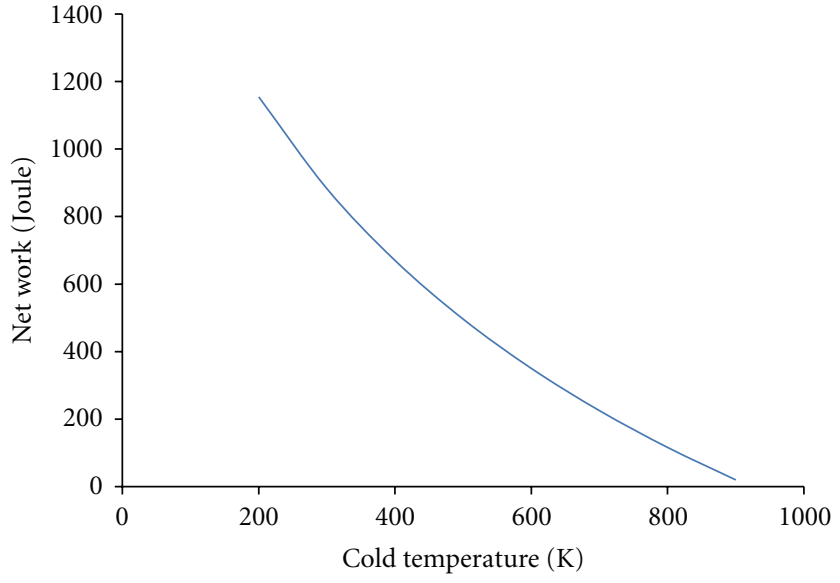

FIGURE 13: Variations of net work against cold temperature.

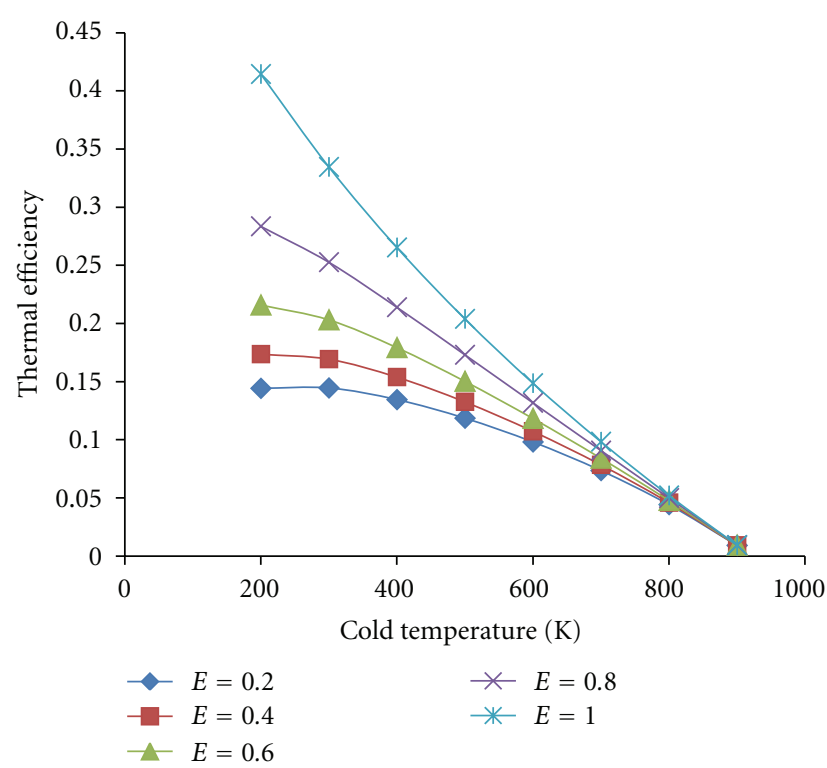

FIGURE 14: Variations of thermal efficiency against cold temperature for different regenerator effectiveness values.

effectiveness will reduce total input heat. In Figure 17, variations of total input heat against regenerator effectiveness for different working fluid are presented. As it is shown, regenerator effectiveness has more effects on air, hydrogen, and nitrogen than helium. For example, the total input heat of nitrogen decreases from 9000 Joule to about 3000 Joule, approximately 66 percent reduction.

It should be considered that, even in these cases, thermal efficiency of helium is much more than other considered working gases. By an increase in regenerator effectiveness, thermal efficiency of all working gases leads to a constant value, see Figure 18.

\subsection{Effects of Phase Angle Difference}

5.5.1. Comparison of Performance Characteristics Variations. In the considered piston arrangement for Stirling engine, the 


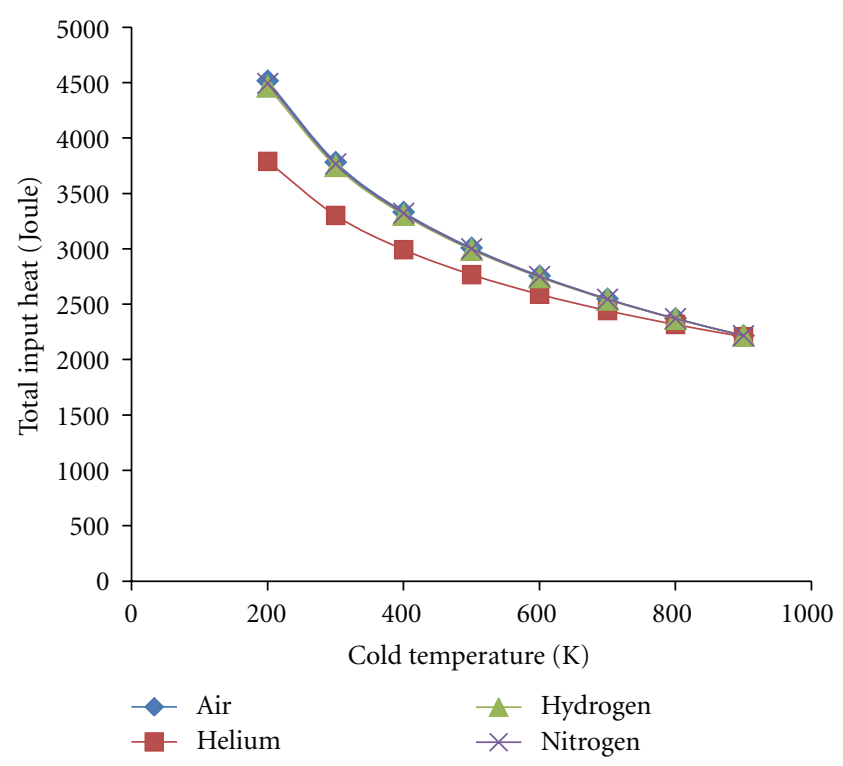

Figure 15: Variations of total input heat against cold temperature for different working gas types.

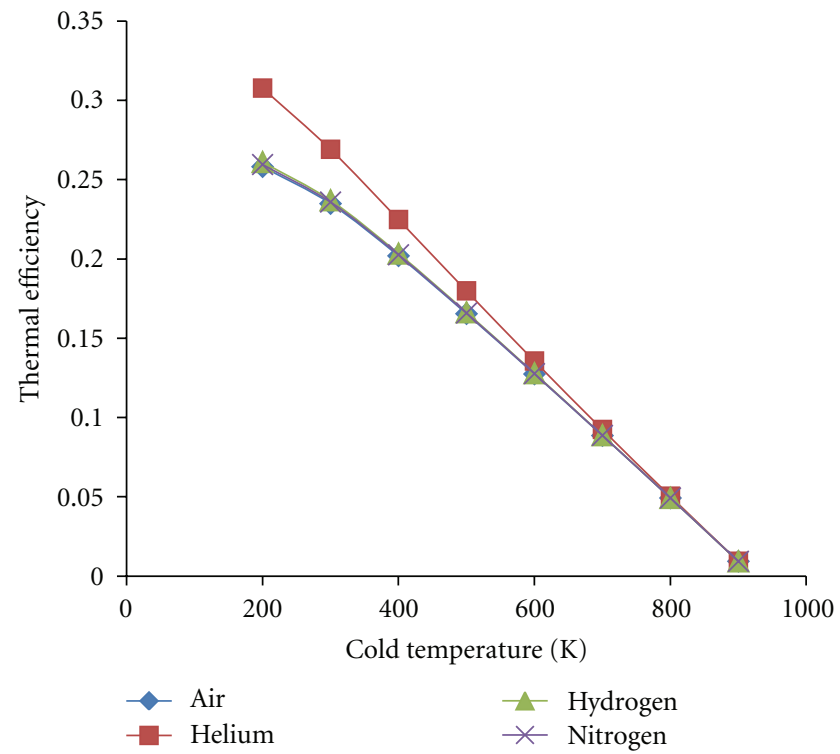

FIGURE 16: Variations of thermal efficiency against cold temperature for different working gas types.

difference angle between hot piston and cold piston is called phase angle difference. In this study, variations of volumes are considered harmonically based on the Simple Harmonic Motion theory [11]. Therefore, phase angle difference has straight effects on volumes variation and, therefore, engine performance. In this section, we are going to find the best phase angle difference to optimize the net work and thermal efficiency. Having appropriate comparable values, we have to normalize net work, total input heat, and thermal efficiency. Therefore, the maximum value is considered in each case as a reference value.

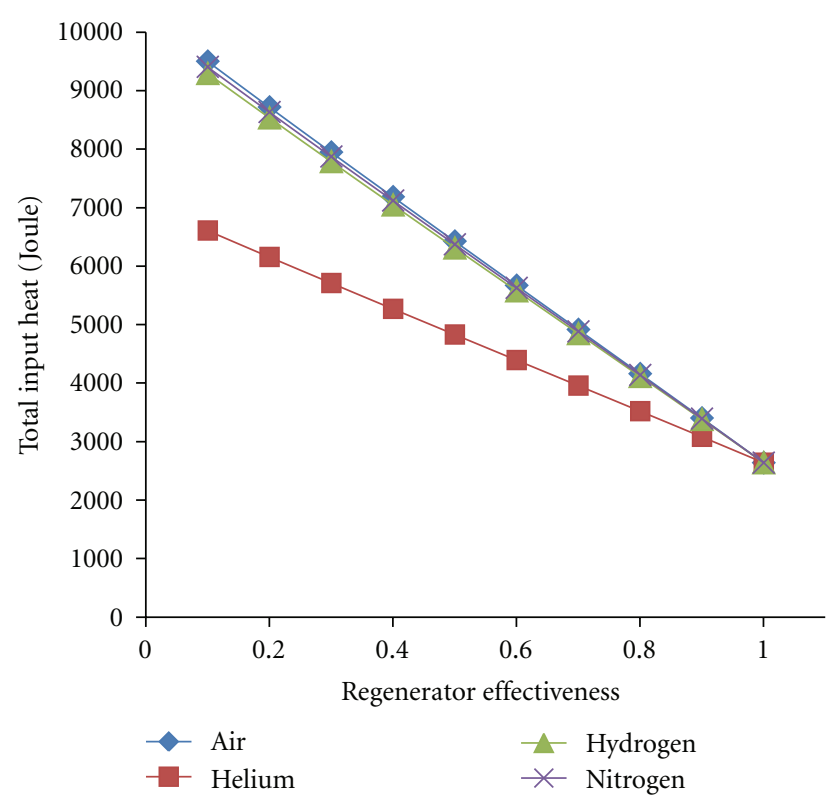

FIGURE 17: Variations of total input heat against regenerator effectiveness for different working gas types.

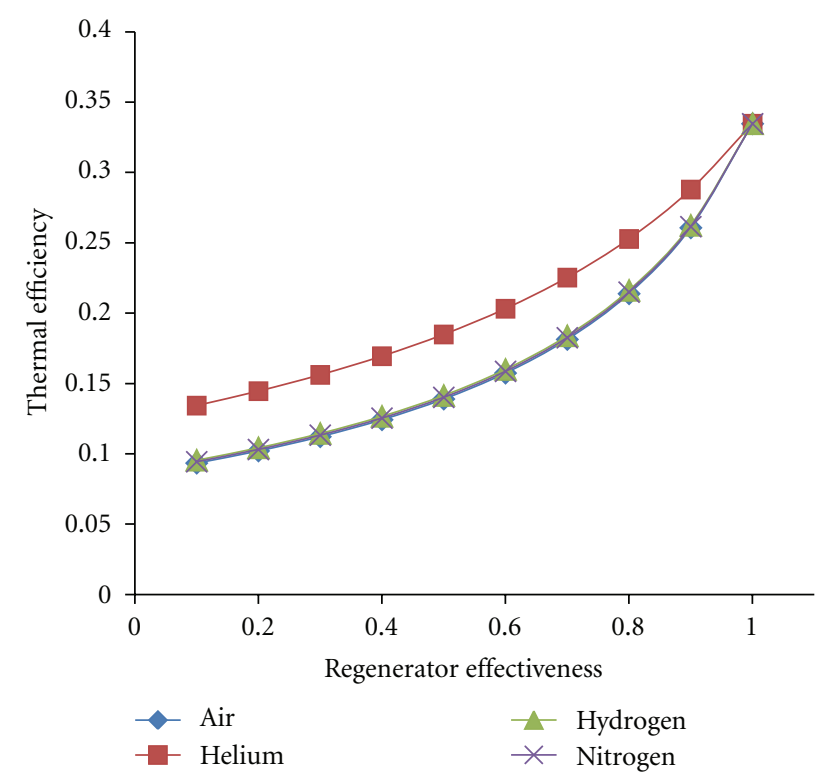

FIGURE 18: Variations of thermal efficiency against regenerator effectiveness for different working gas types.

As it is shown in Figure 19, the maximum value of thermal efficiency can be obtained in ALPH $=110$ degree while the maximum value of net work can be obtained in ALPH $=80$ degree. Being able to follow, the details of normalized net work, total input heat, and thermal efficiency around ALPH $=90$ degree are presented in Table (3). For phase angle difference bigger than 180 degree, the net work and consequently thermal efficiency are negative. This means that engine will use work instead of generating it. 


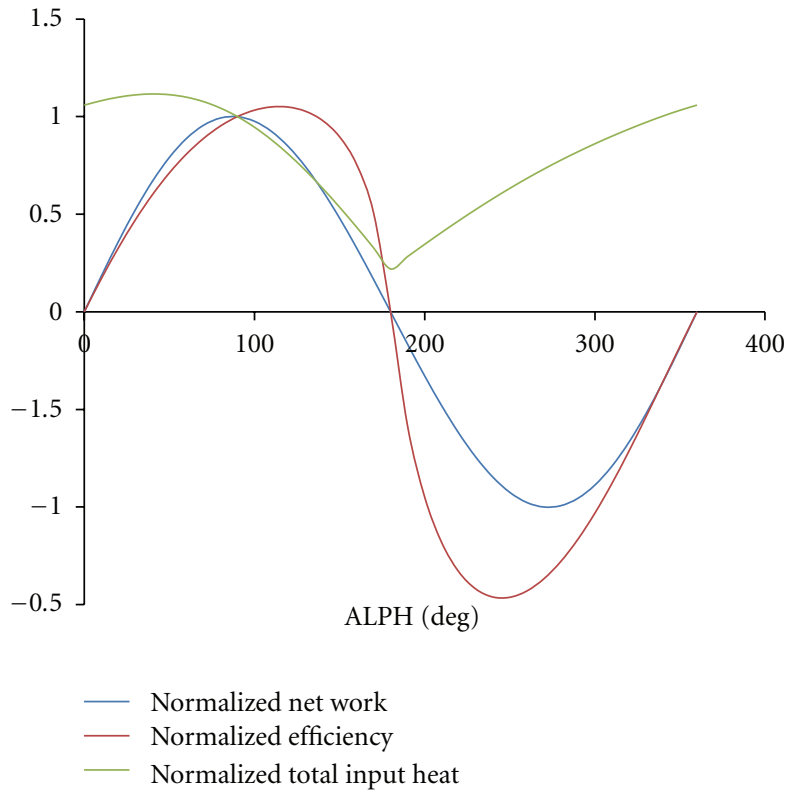

FIGURE 19: Variations of normalized net work, efficiency, and total input heat against difference phase angle.

TABLE 3: Effects of difference phase angle variations on working parameters.

\begin{tabular}{lccc}
\hline ALPH & W-Net & Thermal efficiency & Total input heat \\
\hline 60 & 788.545 & 0.217312 & 3628.62 \\
70 & 848.686 & 0.238807 & 3553.86 \\
80 & 881.95 & 0.256036 & 3444.63 \\
90 & 887.993 & 0.26907 & 3300.23 \\
100 & 867.31 & 0.277903 & 3120.91 \\
110 & 821.141 & 0.282388 & 2907.84 \\
120 & 751.371 & 0.282145 & 2663.07 \\
130 & 660.43 & 0.276402 & 2389.38 \\
140 & 551.199 & 0.2637 & 2090.25 \\
150 & 426.92 & 0.241243 & 1769.67 \\
\hline
\end{tabular}

5.5.2. Effects of Regenerator Effectiveness. To find the optimized value for phase change difference, variations of thermal efficiency in different regenerator effectiveness are shown in Figure 20. As it is presented, optimized value is depended on regenerator effectiveness. For $E=0.2$, ALPH = 90-100 degree is the optimum, while for $E=0.9-0.95$, $\mathrm{ALPH}=150-170$ degree is the optimum point. For $E=1.0$, the optimum point is approximately ALPH $=175$ degree. It should be noted that in reality it is impossible to find ideal regenerator. Ordinary regenerators have effectiveness around $0.5-0.8$ which means that the optimum point is approximately ALPH $=110-130$ degree.

Because the net work is independent from regenerator effectiveness, the optimum point of maximum net work, as stated in Table 3, is approximately ALPH $=80$ degree.

5.5.3. Working Gas Effects. In Figure 21, variations of thermal efficiency against phase angle difference for different working

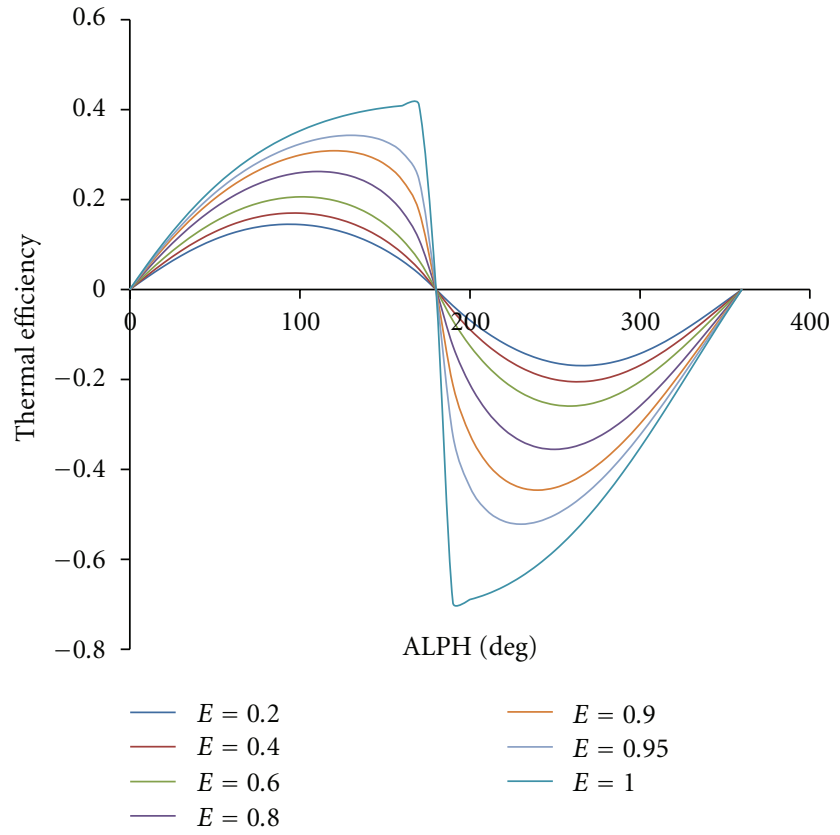

FIGURE 20: Variations of thermal efficiency against difference phase angle for different regenerator effectiveness values.

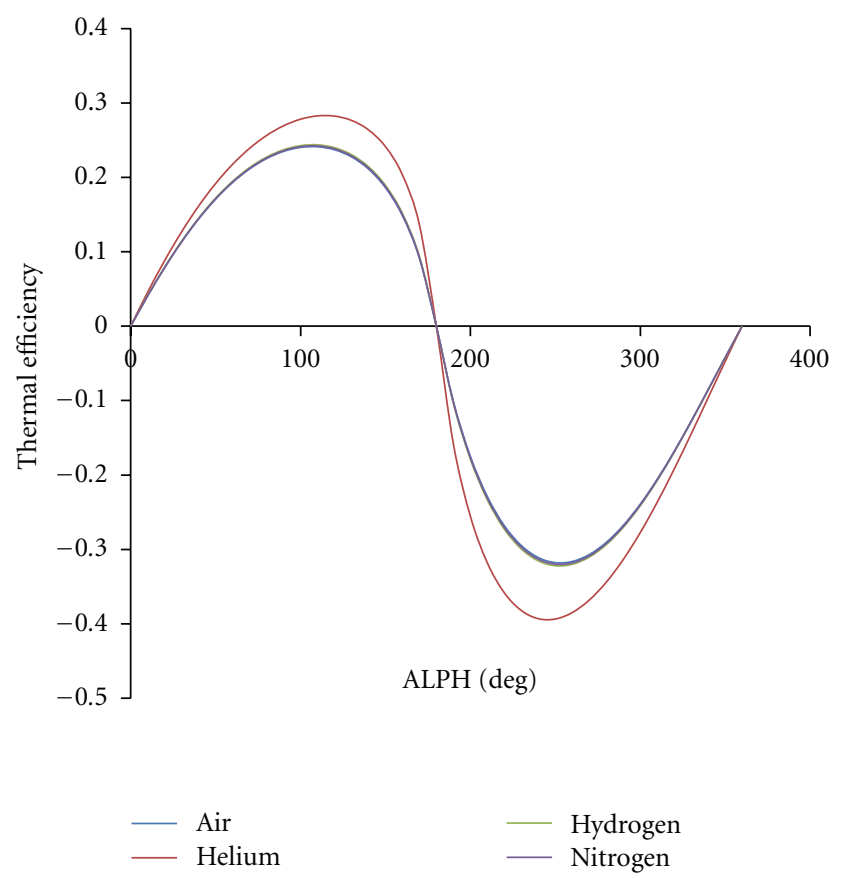

FIGURE 21: Variations of thermal efficiency against difference phase angle for different working gas types.

gas are shown. Thermal efficiency of helium is higher than others in almost all values of phase angle difference.

5.5.4. Work Diagram. In Figure 22, work diagrams for different phase angle difference values are presented. 


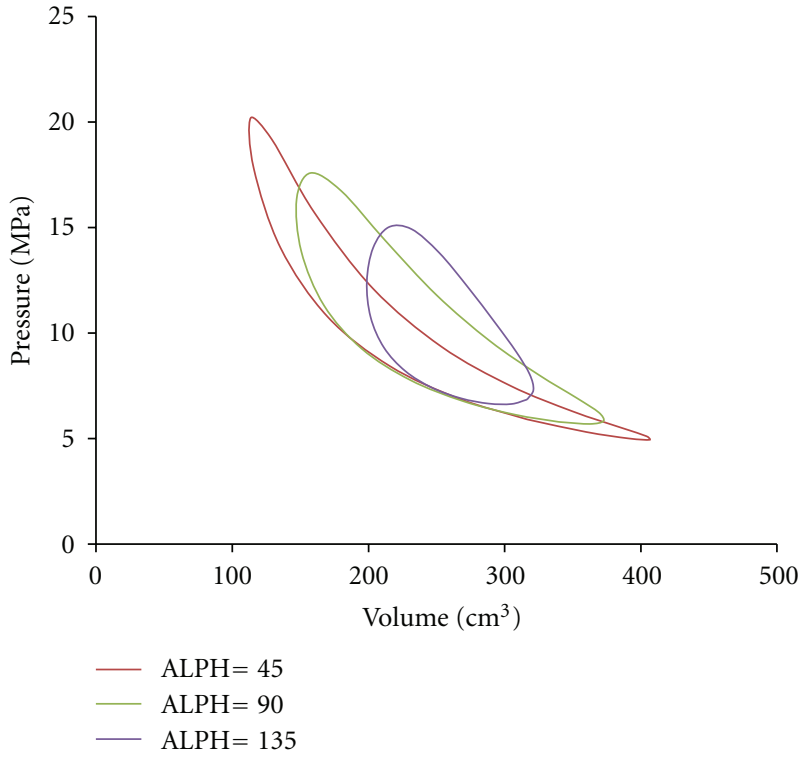

Figure 22: $P-V$ diagram for different phase angle values.

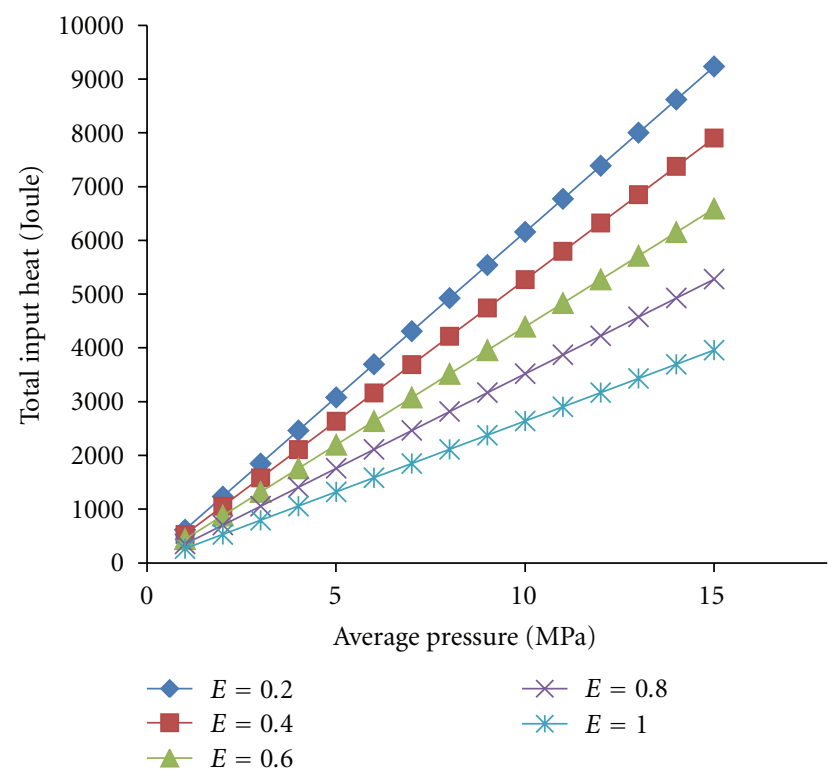

FIGURE 23: Variations of total input heat against average pressure for different regenerator effectiveness values.

\subsection{Effects of Average Pressure}

5.6.1. Effects of Regenerator Effectiveness. Increase in regenerator effectiveness will reduce required heat during process $3^{\prime}-3$. Moreover, this required heat is linearly proportional to working gas mass. Therefore, an increase in average pressure will increase total input heat. These behaviors are presented in Figure 23. Regenerator effectiveness indicates the slope of variations lines. Lower regenerator effectiveness has higher variations line slope.

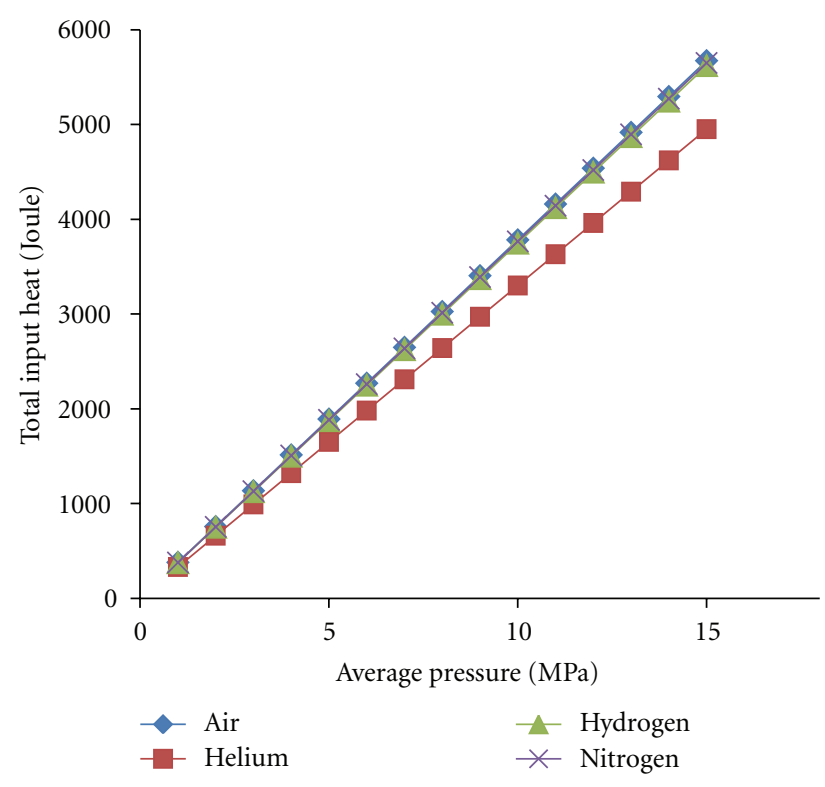

FIGURE 24: Variations of total input heat against average pressure for different working gas types.

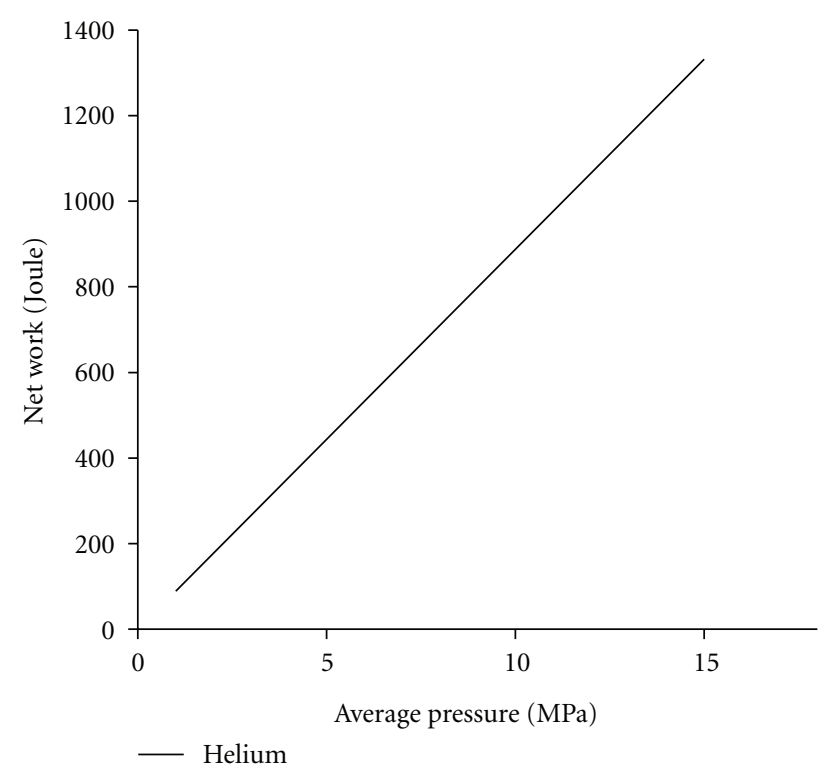

FIGURE 25: Variations of net work against average pressure variations.

5.6.2. Working Gas Effects. In constant volumes and temperature conditions, average pressure has a linear relation with mass of working gas. Therefore, an increase in average pressure will lead to an increase in working fluid mass. Total input heat and net work is linearly proportional to mass of working gas. Therefore, increase in average pressure will result in increase of total input heat and net work which are presented in Figures 24 and 25. While the relations are linear, variations of average pressure do not have effects on thermal efficiency. 


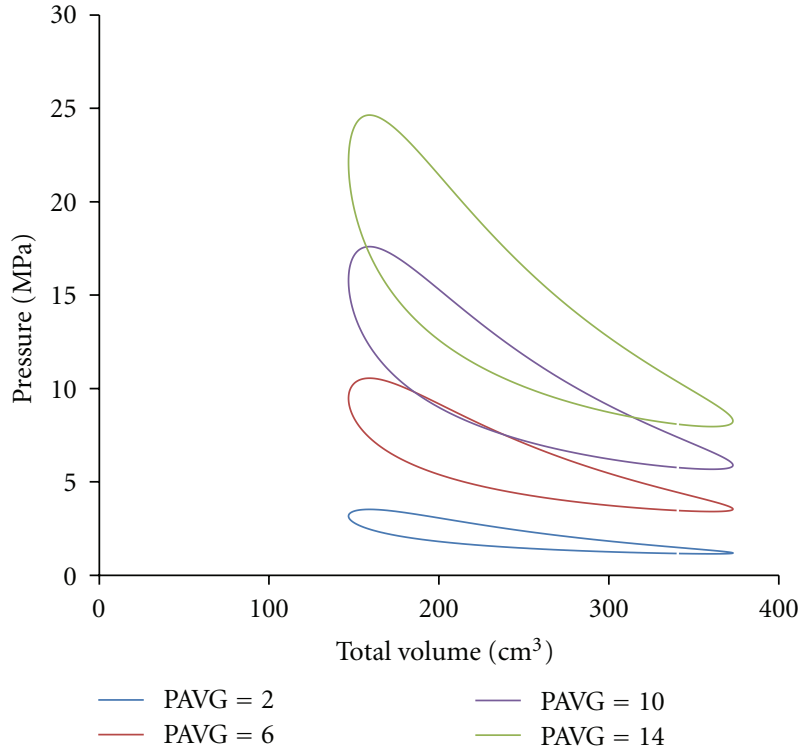

FIGURE 26: Variations of total input heat against total dead volume ratio.

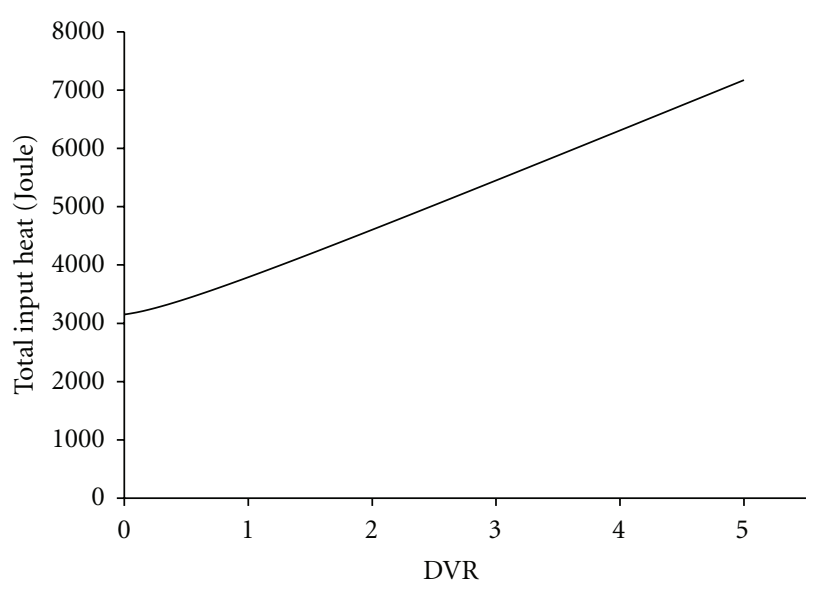

FIgURE 27: Variations of net work against total dead volume ratio.

5.6.3. Work Diagram. In Figure 26, work diagrams for different average pressure values are presented. Variations in average pressure and in mass of working gas are relative (12). Therefore, results of variations in mass of working fluids are not included in this study. In $[11,13]$, results of variations in mass of working fluids are presented.

5.7. Effects of Dead Volume. In Figures 27 and 28, variations of net work and total input heat against dead volume ratio are presented. By increasing dead volume, total input heat increases approximately linearly while the net work decreases exponentially. Therefore, by increasing the dead volume, thermal efficiency will reduce considerably.

To compare rates of variations, normalized working parameters are shown in Figure 29. In dead volume ratios lower than one, decrease rate of net work and thermal efficiency is higher than increased rate of total input heat.

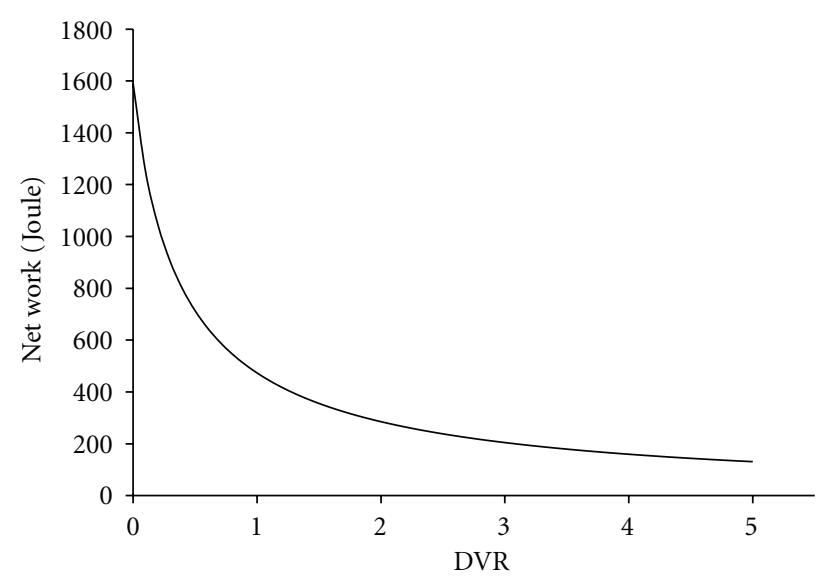

FIGURE 28: Variations of normalized working parameters against total dead volume ratio.

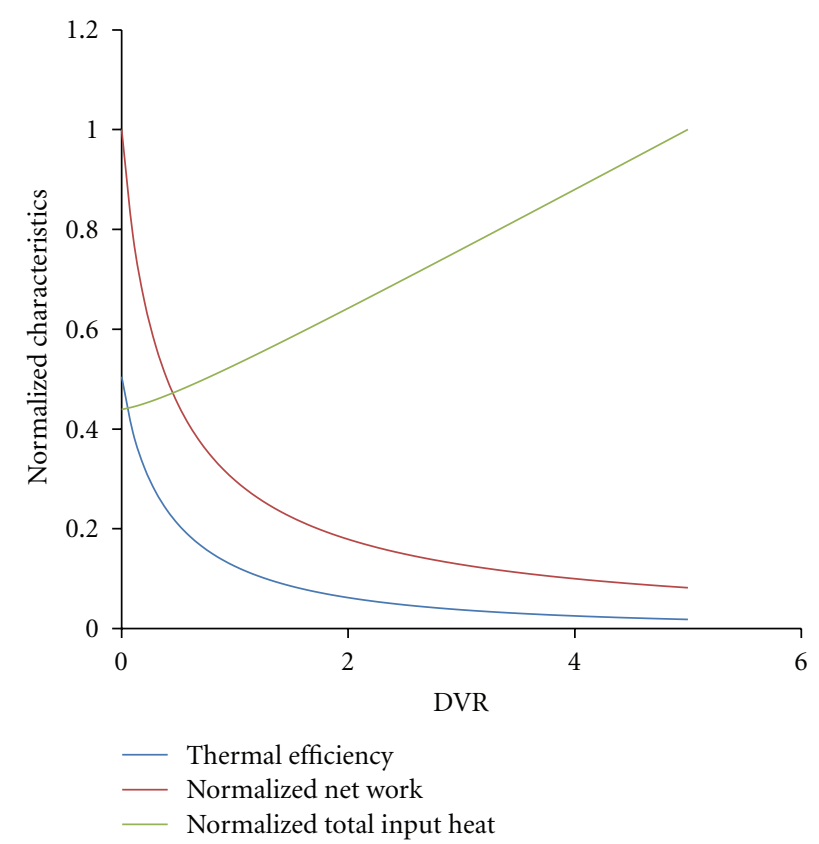

Figure 29: Pressure-Volume diagrams for different average pressure values.

While in dead volume ratios higher than one, increased rate of total input heat is higher.

\section{Conclusion}

In this paper, comprehensive parametric study is performed on the SOLO 161 Solar Stirling Unit. Hot temperature, cold temperature, regenerator effectiveness, working gas, average working pressure, phase change difference, and dead volume values are considered as variable parameters. Along with each parameter effects, interacting effects of these parameters are presented. As a result, the optimal working conditions and engine characteristics can be summarized as follows

(i) An increase in heater temperature will increase thermal efficiency and total input heat. Total input heat 
is increased linearly while the thermal efficiency leads to a limited value. The rate of increase is much more in engines with higher regenerator effectiveness.

(ii) Reduction in cooler temperature will increase thermal efficiency and total input heat. In contrast to heater temperature variations, total input heat is increased exponentially. The rate of total input heat increase is much lower in engines with higher regenerator effectiveness.

(iii) Engines with higher regenerator effectiveness need lower total input heat, and, therefore, have higher thermal efficiency.

(iv) Among the considered working gases, helium has better working characteristics. Due to higher specific heat coefficient, helium needs lower total input heat. Therefore, engines which work with helium have higher efficiency.

(v) Phase angle difference between hot and cold piston shaft has direct effect on the engine performance. For the basic assumed engine, it is observed that around ALPH = 90 degree net work is maximum while the thermal efficiency is maximum in ALPH = 110 degree. Moreover, it is cleared that the optimum ALPH for maximum net work or efficiency is relative to regenerator effectiveness, and working gas type.

(vi) Net work is linearly proportional to average pressure which increase in average pressure leads to an increase in net work. The rate of net work increase is equal to total input heat which means that thermal efficiency is not relative to average pressure. Consider that temperatures and volumes are held constant during these investigations.

(vii) It is observed that an increase in dead volume will result in lower net work and higher total input heat, and, therefore, lower thermal efficiency.

\section{Nomenclature}

$\begin{array}{ll}P: & \text { Pressure } \\ V: & \text { Volume } \\ T: & \text { Temperature } \\ S: & \text { Entropy } \\ R: & \text { Gas Constant } \\ m: & \text { Mass } \\ \text { PAVG: } & \text { Average Pressure } \\ E: & \text { Regenerator Effectiveness } \\ Q: & \text { Heat } \\ W: & \text { Work } \\ \text { ALPH: } & \text { Phase Angle Difference } \\ C_{v}: & \text { Specific Heat at constant Volume } \\ \eta_{\mathrm{th}}: & \text { Efficiency. }\end{array}$

\section{Subscript and Superscript}

$H$ : Related to Hot Side

$C$ : Related to Cold Side

$R$ : Related to Regenerator
HP: Hot Piston

HPSV: Hot Piston Sweep Volume

HPDV: Hot Piston Dead Volume

CP: $\quad$ Cold Piston

CPSV: Cold Piston Sweep Volume

CPDV: Cold Piston Dead Volume

TV: Total Volume

RDV: Regenerator Dead Volume

TDV: Total Dead Volume.

\section{References}

[1] Y. Timoumi, I. Tlili, and S. Ben Nasrallah, "Performance optimization of Stirling engines," Renewable Energy, vol. 33, no. 9, pp. 2134-2144, 2008.

[2] D. G. Thombare and S. K. Verma, "Technological development in the Stirling cycle engines," Renewable and Sustainable Energy Reviews, vol. 12, no. 1, pp. 1-38, 2008.

[3] H. Karabulut, H. S. Yücesu, and C. Çinar, "Nodal analysis of a Stirling engine with concentric piston and displacer," Renewable Energy, vol. 31, no. 13, pp. 2188-2197, 2006.

[4] T. Otaka, I. Kodama, and M. Ota, "Experimental study on a stirling cycle machine of $100 \mathrm{w}$ design capacity," in Proceedings of the International Conference on Power Engineering, Hangzhou, China, October 2007.

[5] B. Kongtragool and S. Wongwises, "Thermodynamic analysis of a Stirling engine including dead volumes of hot space, cold space and regenerator," Renewable Energy, vol. 31, no. 3, pp. 345-359, 2006.

[6] S. K. Andersen, H. Carlsen, and P. G. Thomsen, "Numerical study on optimal Stirling engine regenerator matrix designs taking into account the effects of matrix temperature oscillations," Energy Conversion and Management, vol. 47, no. 7-8, pp. 894-908, 2006.

[7] F. Formosa and G. Despesse, "Analytical model for Stirling cycle machine design," Energy Conversion and Management, vol. 51, no. 10, pp. 1855-1863, 2010.

[8] Z. J. Hu, Z. Y. Li, Q. Li, and Q. Li, "Evaluation of thermal efficiency and energy conversion of thermoacoustic Stirling engines," Energy Conversion and Management, vol. 51, no. 4, pp. 802-812, 2010.

[9] B. Kongtragool and S. Wongwises, "A review of solar-powered Stirling engines and low temperature differential Stirling engines," Renewable and Sustainable Energy Reviews, vol. 7, no. 2, pp. 131-154, 2003.

[10] D. G. Thombare and S. K. Verma, "Technological development in the Stirling cycle engines," Renewable and Sustainable Energy Reviews, vol. 12, no. 1, pp. 1-38, 2008.

[11] W. R. Martini, "Stirling engine design manual," NASA CR135382, 1979, In: M.J. Collie, editor. Stirling engine design and feasibility for automotive use. New Jersey: Noyes data corp.; 1979. p. 60 see also pages 64, 67, 70, 77.

[12] C. Çinar and H. Karabulut, "Manufacturing and testing of a gamma type Stirling engine," Renewable Energy, vol. 30, no. 1, pp. 57-66, 2005.

[13] I. Tlili, Y. Timoumi, and S. B. Nasrallah, "Analysis and design consideration of mean temperature differential Stirling engine for solar application," Renewable Energy, vol. 33, no. 8, pp. 1911-1921, 2008. 

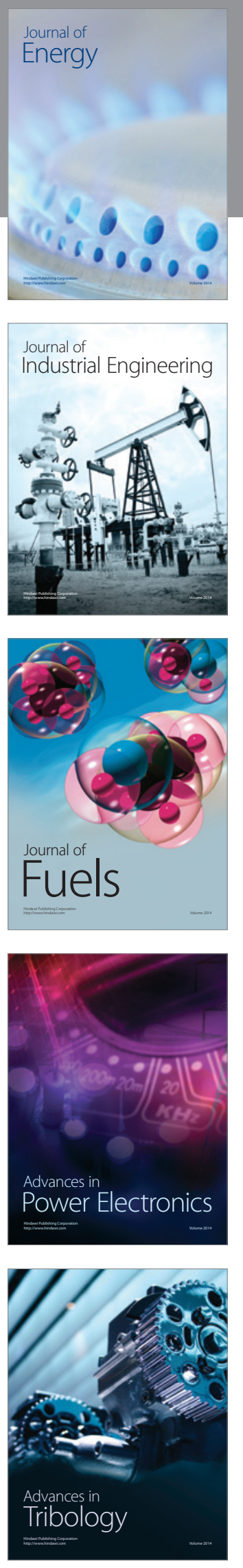
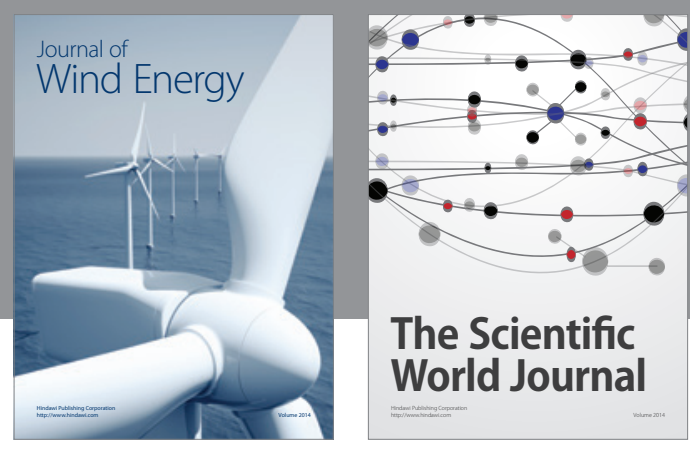

The Scientific World Journal

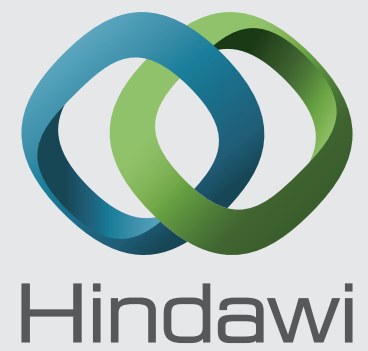

Submit your manuscripts at http://www.hindawi.com
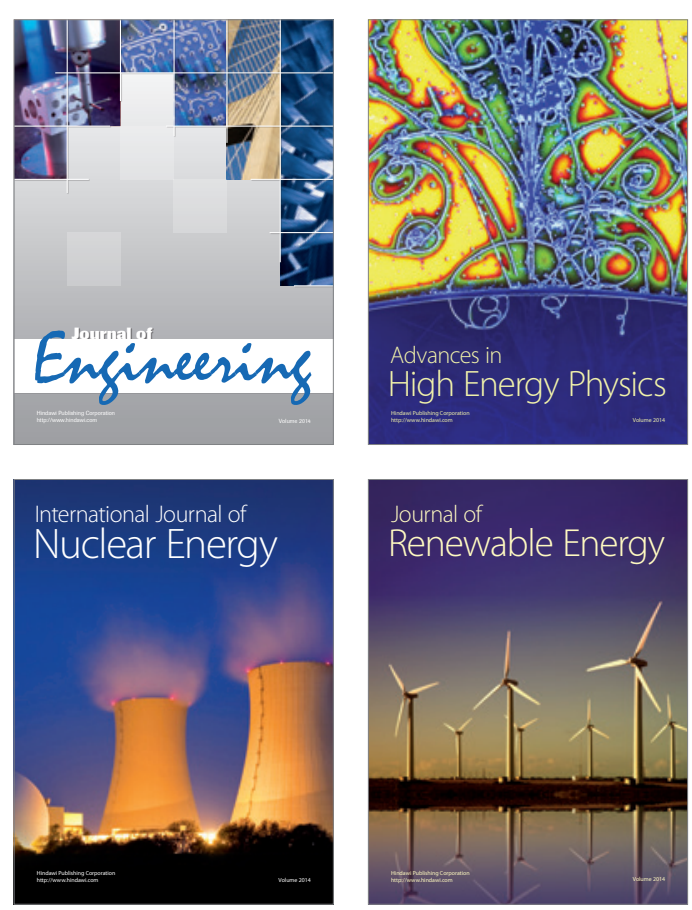

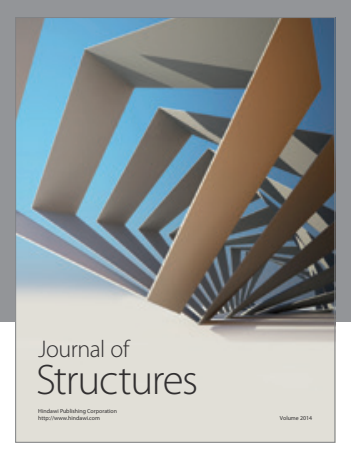

Rotating
Mechinery
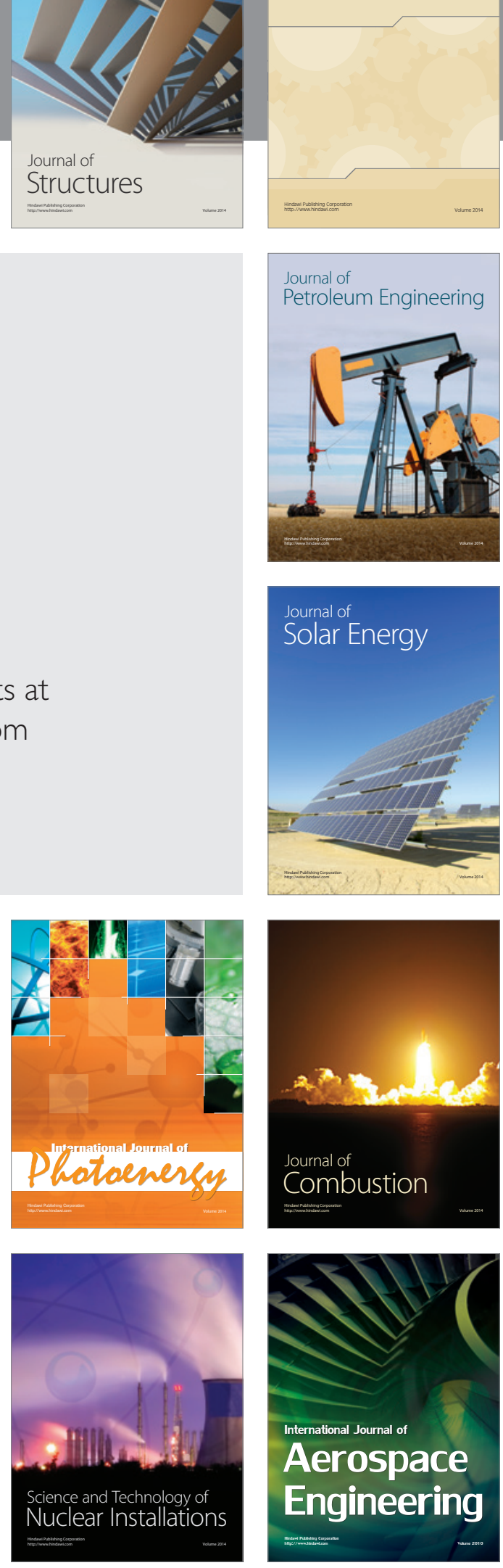